\title{
GFO copywrite: development and testing of written and visual materials for recruiting STEM teachers
}

\author{
Savannah L. Logan, Richard L. Pearson III, and Wendy K. Adams \\ Department of Physics, Colorado School of Mines, 1500 Illinois St, Golden, CO 80401
}

There is a serious shortage of secondary science and math teachers across the United States. Part of this shortage can be attributed to a lack of research-based recruitment materials. To this end, we have developed written and visual materials for recruiting future teachers as part of the Get the Facts Out (GFO) project. We began by working with a marketing expert to develop tag lines, sentences, and other written material based on our research on perceptions of the teaching profession. Over the past year, we have tested these materials with faculty and students at several demographically and geographically diverse US universities. Our findings provide insights into optimal recruitment strategies and highlight the potential need for unique recruitment materials based on location, demographics, and target audience. 


\section{INTRODUCTION}

The United States is facing a serious shortage of qualified middle and high school teachers in the STEM disciplines (science, technology, engineering, and mathematics) [1]. This shortage is a major limitation to improving pre-college STEM preparation; based on ACT test score data, an alarming $80 \%$ of 2018 high school graduates do not meet the STEM Readiness Benchmark, and only $2 \%$ of underserved students meet the STEM benchmark [2]. This, in turn, leads to lowered retention rates for college STEM majors $[3,4]$ and ultimately creates a shortage of qualified college graduates to meet growing demands for STEM majors in the workforce [5]. Recruiting and retaining a larger number of qualified STEM teachers at the middle and high school levels will increase the number of successful STEM graduates at the college level and ultimately enhance science literacy across the United States.

A recent study revealed that about half of STEM majors at US universities report some level of interest in becoming a middle or high school teacher [6]. In spite of this fact, the vast majority of interested STEM majors chose not to pursue a career in teaching; $66 \%$ of chemistry teachers, $63 \%$ of physics teachers, and $38 \%$ of math teachers either do not have a major in their field or do not have teacher certification [7]. Recent research suggests that this apparent contradiction is largely the result of misperceptions about the teaching profession among college students and faculty $[8,9]$. While many misperceptions exist, the majority are centered around teacher salaries, benefits, and job and life satisfaction. Fortunately, there is a substantial body of national data that contradicts these negative misperceptions. Furthermore, we have found that when this data about the teaching profession is shared, a much larger fraction of STEM students seriously consider careers in teaching.

The Get the Facts Out (GFO) campaign began in 2017 with the premise that faculty can help solve the nationwide STEM teacher shortage by addressing misperceptions about the teaching profession, thereby opening the door to this career option for the large pool of interested STEM students. Principal investigator Wendy Adams partnered with four national societies (the American Physical Society, the American Association of Physics Teachers, The Mathematical Association of America, and The American Chemical Society) to build resources to help faculty combat the major misperceptions about teaching careers among undergraduate and graduate students. These misperceptions were identified during the development and validation of the Perceptions of Teaching as a Profession (PTaP) survey.

Through the GFO campaign, we have identified a large body of data that reveals key facts about the teaching profession that can be used to correct misperceptions. These facts have been used to develop tag lines, statements, and other written materials that can be displayed in various forms to reach faculty and students across the United States.
To develop the strongest possible STEM teacher recruitment materials, we began by identifying existing resources. We found this body of work to be relatively small and were not able to find any resources that were researchbased or user-tested. In part this lack of resources can be explained by the recent T-TEP report, which found that "Few physics departments and schools of teacher education are actively engaged in the recruitment... of physics teachers" [10]. The recruitment resources that we did find included resources from The Physics Teacher Education Coalition (PhysTEC) [11], 100Kin10 [12], TEACH.org [13], the American Association of Physics Teachers (AAPT) [14] and a general teacher recruitment book published by the National Council on Teacher Quality [15].

Our recruitment materials have been tested and refined in an iterative process via student and faculty interviews, focus groups, and surveys conducted at several demographically and geographically diverse US institutions. Our results reveal subtle variations in reactions to materials based on location, and moderate variations between faculty and students. Key insights include that students react most positively to representations of teaching as a professional endeavor, that negative statements should never be used in recruitment materials (even if they are subsequently debunked) and that, to be most effective, unique materials must be developed for faculty and for students.

\section{RESEARCH QUESTIONS}

While the GFO campaign aims to answer many questions related to perceptions, recruitment, and retention of teachers, here we focus on a small subset of these questions:

(1) What written and visual materials work best for improving perceptions of the teaching profession and thereby recruiting future STEM teachers?

(2) Do location or demographics play a role in the success of written and visual materials?

(3) Do faculty and students react differently to written and visual materials?

\section{DEVELOPMENT AND TESTING OF RECRUITMENT MATERIALS}

\section{A. Phase I: Initial development and testing of materials using interviews and surveys}

We began by developing "Did you know..." statements to counter the misperceptions identified during the development and validation of the PTaP. For example, "Did you know... that there are student loan forgiveness programs and scholarships for math and science teachers?" We collected additional materials from other STEM teacher recruitment projects such as 100Kin10's "Blow Minds! Teach STEM." Campaign, PhysTEC, and AAPT. As we developed resources such as posters and brochures, we 
worked to locate professional-quality, high-impact images from our programs and from stock photos. In addition, we collected testimonials and other written materials from practicing teachers and other recruitment resources.

\section{1. “Did you know..." and tagline user-testing}

After we identified a set of "Did you know..." statements and taglines, we conducted five student interviews followed by an online survey at two institutions of higher education. Individual student interviews were conducted to verify that the "Did you know..." statements were interpreted consistently and correctly and to determine whether each statement elicited positive or negative feelings about the teaching profession.

Following these student interviews, we conducted an online survey of over 150 STEM undergraduate and graduate students. We asked whether the respondent intended to become a teacher, then the survey read: "We would like your help in understanding if we've created positive messages. Please provide your candid opinion on how each of these statements makes you feel." Following is an example of a survey statement and possible responses:

1. Did you know... most teaching jobs have better retirement benefits than private industry?

$\begin{array}{lll}\text { This adds to my } & \text { Neutral. } & \begin{array}{l}\text { This subtracts from my } \\ \text { opinion of teaching. }\end{array}\end{array}$

After the initial survey section, we asked students to rank all of the "Did you know..." statements; we also collected additional data on each "Did you know...", asked for their favorite three taglines, and elicited tagline suggestions.

\section{Image and look and feel user-testing}

During our initial testing, we also conducted thirteen interviews to identify engaging photos and an effective "look and feel." In these interviews, we tested the look and feel by showing imagery from the 100Kin10 "Blow minds! Teach STEM." campaign, the U.S. Army Marketing and Advertising Program, TEACH.org video advertisements, and TEACH.org posters created for the GFO campaign. We tested individual images by showing posters featuring each image. In both cases, we then asked the subject to think out loud as they studied the imagery or photo. We also asked, "Does this give you a positive or negative feeling about the teaching profession?" and, "Would you stop to look at this poster?"

\section{B. Phase II: Refinement and testing of materials using focus groups at diverse institutions}

Additional misperceptions were revealed through interviews with faculty members at institutions in Colorado and Oregon as part of the development and validation of the Faculty PTaP. Our research team worked with a marketing expert to develop additional "Did you know..." statements about the teaching profession that contained emotional hooks to counter these misperceptions.

Our copywrite materials for teacher recruitment now include "Did you know..." statements, taglines, presentation titles, testimonials, and other positive statements about the teaching profession. After this further development and refinement of our teacher recruitment materials, we conducted focus groups to test our materials with faculty and students at four demographically and geographically diverse institutions: the Colorado School of Mines, California State University - Long Beach, Chicago State University, and West Virginia University. Table I indicates enrollment statistics, demographics, and the highest degree offered in physics, chemistry, and math at each institution.

Focus groups were conducted in Fall 2018 and Spring 2019. In total, 28 faculty and 34 students participated in a total of nine focus groups to test our materials. While the numbers varied slightly based on refinements to our materials, each focus group tested around 50 written statements and 9 images meant to improve perceptions of the teaching profession. Focus groups at the Colorado School of Mines were used largely for refinement and modification of materials, so the data from those groups is not included in our final results.

TABLE I. Institutional Statistics. Total student enrollment, percentages of students who identify as Hispanic, black, Asian, white, and two+ races, and highest degrees offered in physics, chemistry, and math at the four institutions at which focus groups were conducted $[16,17]$.

\begin{tabular}{|c|c|c|c|c|c|c|c|c|}
\hline Institution & Enrollment & Hispanic & Black & Asian & White & Two+ & $\begin{array}{l}\text { Physics } \\
\text { /Chem. }\end{array}$ & Math \\
\hline $\begin{array}{c}\text { Chicago State } \\
\text { University }\end{array}$ & 2,029 & $8 \%$ & $75 \%$ & $1 \%$ & $3 \%$ & $0 \%$ & B.S. & M.S. \\
\hline $\begin{array}{l}\text { Colorado School } \\
\text { of Mines }\end{array}$ & 4,794 & $7 \%$ & $1 \%$ & $5 \%$ & $75 \%$ & $5 \%$ & Ph.D. & Ph.D. \\
\hline $\begin{array}{c}\text { West Virginia } \\
\text { University }\end{array}$ & 22,504 & $4 \%$ & $5 \%$ & $1 \%$ & $81 \%$ & $3 \%$ & Ph.D. & Ph.D. \\
\hline $\begin{array}{c}\text { California State } \\
\text { University - Long } \\
\text { Beach }\end{array}$ & 31,351 & $39 \%$ & $4 \%$ & $23 \%$ & $19 \%$ & $5 \%$ & M.S. & M.S. \\
\hline
\end{tabular}




\section{Focus group methods}

In each focus group, written and visual materials were displayed on a screen at the front of a classroom, with written materials divided into categories based on their type ("Did you know..." statements, taglines, presentation titles, etc.). Participants were given worksheets and asked to silently write whether each statement increased, decreased or did not change their opinion of the teaching profession. After each section, a short group discussion was facilitated to collect additional opinions and determine why each statement elicited a positive or negative response. After discussing written materials, a short discussion was facilitated around visual materials. These materials generally included pictures of teachers, students, and classrooms that could be used on recruitment posters or in brochures.

\section{RESULTS}

\section{A. Phase I: "Did you know..." and tagline user- testing}

The data revealed that we had a strong set of "Did you know..." statements but relatively weak taglines. When analyzing the "Did you know..." survey results, we sorted responses into three bins based on the type of respondent: those who intended to teach grade 7-12, those who were not sure, and those who did not intend to become teachers. We then identified the top ten "Did you know..." statements for each group and found eight that appeared in all three bins (see Table II for the top four statements). In addition, we eliminated any statements that produced a negative reaction in $10 \%$ or more of the respondents.

Only five of the thirteen taglines tested well enough to use in recruitment materials. Some of the poorly received taglines, such as "What's stopping you from teaching the next generation?" encouraged respondents to compile a mental list of why they might not want to teach, even if they intended to become teachers. The overwhelming favorite tagline was "Blow minds! Teach science." This was a modification to 100Kin10's "Blow Minds! Teach STEM." campaign tagline. We modified 100Kin10's statement, from "Teach STEM" to "Teach science," because "Teach STEM" was consistently received poorly in student interviews. The typical response was "I don't want to teach STEM, I want to teach science (or math). ” In many high schools, STEM is a subject of its own (separate from math and science classes), and most of our interviewees did not want to teach this subject. This may, in part, explain the poor response to the "Blow Minds! Teach STEM." campaign and reaffirms the need for user-testing of recruitment materials. Table II indicates student responses to our initial "Did you know..." statement testing.
TABLE II. Initial "Did you know..." statement rankings. Results are based on an online survey collected from STEM students at the University of Northern Colorado and the Colorado School of Mines. The overall rank for all students is indicated, as well as the statement's rank for students who did, did not, or might want to become a teacher $\left(n=33,32,33 ; n_{\text {total }}=98\right)$.

\begin{tabular}{lcccc}
\hline \hline & \multicolumn{3}{c}{ Ranking } \\
"Did you know..." & All & Yes & Maybe & No \\
\hline $\begin{array}{l}\text { "That there are student } \\
\text { loan forgiveness programs } \\
\text { and scholarships for math } \\
\text { and science teachers?" }\end{array}$ & 1 & 7 & 2 & 1 \\
$\begin{array}{l}\text { "Most teaching jobs have } \\
\text { better retirement benefits } \\
\text { than private industry?" }\end{array}$ & 2 & 8 & 2 & 5 \\
"You can get a job almost \\
$\begin{array}{l}\text { anywhere as a science or } \\
\text { math teacher?" }\end{array}$ & 3 & 1 & 9 & 2 \\
$\begin{array}{l}\text { "Science teachers report } \\
\text { having higher overall job } \\
\text { satisfaction than other } \\
\text { STEM professionals?" }\end{array}$ & 4 & 4 & 1 & 3 \\
\hline \hline
\end{tabular}

\section{B. Phase I: Image and look and feel user-testing}

Student responses to the look-and-feel testing were consistent in that all subjects preferred the presentation of teaching as a serious career option, similar to the U.S. Army marketing approach. Materials that used cartoonish imagery or "hip" language were not well received. When comparing a poster using comic sans font to a poster using Calibri font, respondents indicated that the former must be about elementary teaching.

Identifying effective images to use on teacher recruitment posters and brochures has been a formidable challenge, in part because faculty and students respond very differently to photos. Faculty are concerned with how the photograph represents the profession (they tend to like group work shots) and would like to see subjects that are underrepresented in their field (e.g. women and minorities in physics). Overall, faculty members have gravitated toward stock photos of diverse groups doing lab work. Students are interested in excited, smiling people, with a strong preference for focused shots of teachers in action. All student interviewees indicated that stock photos look fake and give them a negative view of the material presented on the poster. For both faculty and students, background content is important; if a photo contains anyone who looks unhappy or distracted, both groups rate it poorly.

\section{Phase II: Focus groups at diverse institutions}

Overall, we found only subtle variations between locations in our focus groups, and moderate variations 
between student and faculty responses to our copywrite materials. Our materials generally increased participants' opinions of the teaching profession, although a surprisingly large percentage (33\% for students and $37.5 \%$ for faculty) generated a neutral, mixed, or mostly negative response. Our taglines similarly varied in success; samples of very successful, mixed, and very unsuccessful taglines are included in Table III.

TABLE III. Student reactions to select teacher recruitment taglines. These numbers are from focus groups conducted at Chicago State University, California State University - Long Beach, and West Virginia University, and included a total of 16 participants.

\begin{tabular}{lccc}
\hline \hline Written Material Tested & $\begin{array}{c}\% \\
\text { Decrease }\end{array}$ & $\begin{array}{c}\% \\
\text { Neutral }\end{array}$ & $\begin{array}{c}\% \\
\text { Increase }\end{array}$ \\
\hline $\begin{array}{l}\text { Inspire young minds. } \\
\text { Teach science. }\end{array}$ & $0 \%$ & $6 \%$ & $94 \%$ \\
$\begin{array}{l}\text { Be happy. Teach science. } \\
\begin{array}{l}\text { Those who can, do. Those } \\
\text { who can also inspire, } \\
\text { teach! }\end{array}\end{array}$ & $12 \%$ & $47 \%$ & $41 \%$ \\
\hline \hline
\end{tabular}

A general theme that emerged from our focus groups was that any statement that suggested negativity about the teaching profession either subtracted from or did not change opinions for a large number of students. For example, the tagline "Those who can, do. Those who can also inspire, teach!" generated a mostly negative response from students. Similarly, the statement "Did you know... most people underestimate teacher salaries and overestimate private sector salaries, creating an exaggerated perceived pay gap?" was largely neutral for students. Confirming our results from Phase I, the most successful "Did you know..." statements for students were numbers 1,2 , and 3 in Table II. The top performing faculty statement was "Did you know... Teachers rate their lives better than all other occupation groups, trailing only physicians?" This may reflect differing values for students and faculty.

We also found that faculty and students generally have moderately different responses to written materials. For example, the phrase "Did you know... grade 7-12 teaching is highly complex and engaging work?" was one of the most positive statements for faculty, while for students it consistently generated a negative response. This divergence of responses occurred for approximately $27 \%$ of the materials we tested with both groups. Consistent with Phase I work, faculty and students had strongly differing opinions on visual materials.

Finally, we found several weak correlations between specific materials and locations or demographics. For example, the tagline "Blow Minds! Teach Science." tested extremely well in Colorado and Long Beach, but tested extremely poorly with all groups in West Virginia due to an association between "blow minds" and drug use. We also saw some correlation between preferred visual materials and demographics; for example, photos of African American students tested well in Chicago and Long Beach but were seen as stock photos in West Virginia.

\section{FUTURE WORK}

While the aforementioned focus groups, interviews, and surveys have provided great insights into the effectiveness of our teacher recruitment materials, they included a relatively small number of participants and institutions. To collect large-scale data on the effectiveness of our materials, we are developing an online survey to be administered to students and faculty nationwide. Through this national survey, we hope to identify positive, emotionally appealing wording that can be used across the nation, as well as to gain more concrete insights into variations in reactions based on location and demographics.

\section{CONCLUSIONS}

There is a shortage of STEM teachers in the United States, and this issue must be addressed in order to increase the number of successful STEM graduates from our institutes of higher education and to improve science literacy more broadly in our country. Recent research [8] has determined that misperceptions about the teaching profession, such as underestimates of teacher salaries and job satisfaction compared to private industry, are a major factor in dissuading qualified STEM graduates from pursuing teaching careers. The Get the Facts Out (GFO) campaign aims to measure and correct these misperceptions about the teaching profession in order to recruit more STEM teachers, and the subset of the GFO campaign addressed in this paper is aimed at developing research-based STEM teacher recruitment materials. Through interviews and focus groups at diverse institutions, we have found that our materials have a general positive impact on views of the profession, although certain factors within materials, such as negative statements or less engaging images, will decrease effectiveness. In the future, we will refine our materials through the development of a national online survey; using the results of this survey, we will create and distribute ready-to-go, research-based teacher recruitment materials to universities across the country. We hope that this will ultimately help address the STEM teacher shortage and improve retention and preparation for STEM students nationwide.

\section{ACKNOWLEDGMENTS}

The authors would like to thank Kristine Callan, Mark Ferguson, Drew Isola, Zach Levine, Alex Miller, Monica Plisch, Gay Stewart, Terri Taylor, and Rebecca Vieyra for their contributions to this work. This work is supported by NSF DUE-1821710. 
[1] F. Cross, Teacher Shortage Areas Nationwide Listing 19901991 through 2017-2018 (U.S. Department of Education, Washington, DC, 2017). Retrieved July 1, 2019 from https://www2.ed.gov/about/offices/list/ope/pol/ateachershort ageareasreport2017-18.pdf.

[2] ACT, The Condition of College \& Career Readiness National 2018 (ACT, 2018). Retrieved July 1, 2019 from https://www.act.org/content/dam/act/unsecured/documents/c ccr2018/National-CCCR-2018.pdf.

[3] President's Council of Advisors on Science and Technology, Engage to Excel: Producing One Million Additional College Graduates with Degrees in Science, Technology, Engineering, and Mathematics (Office of Science and Technology, Washington, DC, 2012).

[4] E. Seymour and N. M. Hewitt, Talking about Leaving: Why Undergraduates Leave the Sciences. Westview Press, 1997.

[5] National Science Board, Science and Engineering Indicators 2016 (NSB-2016-1) (National Science Foundation, Arlington, VA, 2016).

[6] M. Marder, R. C. Brown, and M. Plisch, Recruiting Teachers in High-Needs STEM Fields: A Survey of Current Majors and Recent STEM Graduates, A Report for the American Physical Society Panel on Public Affairs (American Physical Society, College Park, MD, 2017).

[7] J. Hill and C. Owens, Education and Certification Qualifications of Departmentalized Public High SchoolLevel Teachers of Selected Subjects: Evidence from the 2011-12 Schools and Staffing Survey (NCES 2015-814) (National Center for Education Statistics, U.S. Department of Education, Washington, DC, 2015).

[8] W.K. Adams, A new survey uncovers strong misperceptions about the teaching profession. What can we do to get the facts out? APS Forum on Education Fall 2017 Newsletter (2017).

[9] B. Auguste, P. Kihn, and M. Miller, Closing the Talent Gap: Attracting and Retaining Top-Third Graduates to Careers in Teaching (McKinsey \& Company, 2010). Retrieved July 1, 2019 from http://www.mckinseyonsociety.com/downloads/reports/Edu cation/Closing_the_talent_gap.pdf.

[10] D. E. Meltzer, \& V. K. Otero, Transforming the preparation of physics teachers. (APS 2014)

[11] See www.phystec.org/keycomponents/recruitment/, Retrieved September 28, 2019

[12] See blowmindsteachstem.com/learn.html. Retrieved July 1, 2019.

[13] See Teach.org. Retrieved September 28, 2019

[14] The on-line AAPT teacher recruitment materials used in the initial phases of this project were replaced with GFO resources in 2019 so are no longer available.

[15] D. Brown, R. Rickenbrode, \& K. Walsh, Start Here to Become a Teacher (2019 NCTQ)

[16] See www.usnews.com. Retrieved July 1, 2019.

[17] See www.collegesimply.com. Retrieved July 1, 2019. 